\title{
Reproducibility of the multi-component aspect of species diversity across different areas and scales: towards the constitution of a shortlist of complementary indices for monitoring fish diversity?
}

\author{
Jean-Claude Gaertner, ${ }^{1,}{ }^{*}$ Bastien Mérigot, ${ }^{1}$ Giulio Rélini, ${ }^{2}$ Jacques A. Bertrand, ${ }^{3}$ Nabila Mazouni, ${ }^{4}$ \\ Chrissi-Yianna Politou, ${ }^{5}$ Luis Gil de Sola, ${ }^{6}$ Argyris Kallianiotis, ${ }^{7}$ Paolo Carpentieri, ${ }^{8}$ Matteo Murenu, ${ }^{9}$ \\ Jean-Pierre Durbec ${ }^{1}$, Nedo $\operatorname{Vrgoc}^{10}$ and Nicola Ungaro ${ }^{11}$
}

${ }^{1}$ Centre d'Océanologie de Marseille, LMGEM, UMR CNRS 6117, Université de la Méditerranée, Campus de Luminy, 13009 Marseille, France

${ }^{2}$ Universita di Genova, Via Baldi 5, 16126 Genoa, Italy

${ }^{3}$ IFREMER, Research Center Martinique (FWI), Pointe-Fort, 97231 Le Robert, France

${ }^{4}$ Université de Polynésie Française, Laboratoire de Biodiversité Terrestre et Marine (BIOTEM) BP 6570. 98702 FAA'A Aéroport. TAHITI - Polynésie française

${ }^{5}$ Hellenic Center for Marine Research, Institute of Marine Biological Resources, Agios Kosmas, 16777 Helliniko, Greece

${ }^{6}$ Centro Oceanográphico de Málaga (IEO), Puerto pesquero s/n, 29640 Fuengirola (Malaga), Spain

${ }^{7}$ National Agricultural Research Foundation, Fisheries Research Institute, 64007 Kavala, Greece

${ }^{8}$ Department of Animal and Human Biology, University of Rome "La Sapienza", V.le dell'Università, 32, 00185 Rome, Italy

${ }^{9}$ Department of Animal Biology and Ecology, University of Cagliari, Viale Poetto, 1, Italy

${ }^{10}$ Split Institute of Oceanography and Fisheries, Šet. I. Meštrovića 63, Split, Croatia

${ }^{11}$ Department of Animal Production, University of Bari, I-70125 Bari, Italy

*: Corresponding author : Jean-Claude Gaertner, email address : gaertner@univmed.fr

\begin{abstract}
:
Recent theoretical and field studies conducted in both terrestrial and marine ecosystems have suggested that diversity could be a more complex and multi-component concept than previously thought. However, it is still poorly understood to what extent the information provided by the various indices is complementary with regard to diversity, and to what extent this complementarity is reproducible in different situations or at different scales of observation. In the present work, we have analysed the reproducibility of the empirical relationships between 11 diversity indices related to four major aspects (components) of species diversity (species richness, rarity, evenness and species taxonomy) in order to determine whether there is a general pattern of redundancy or complementarity in diversity measures that holds across years, areas and spatial scales. We have applied this approach to groundfish diversity through the analysis of 2404 trawl hauls collected during the first large-scale annual surveys carried out using a single sampling design throughout the northern Mediterranean Sea (ranging from 36.3 to $45.7^{\circ} \mathrm{N}$, and $5.3^{\circ} \mathrm{W}$ to $28^{\circ} \mathrm{E}$ ). Whatever the years, areas and
\end{abstract}


scales studied, we found a strong reproducibility in the number and the nature of the main complementary components of diversity. The whole set of diversity indices considered may be roughly split into 6 complementary groups of descriptors. This result highlights that, in contrast to what is still the usual practice, monitoring diversity should not be based on only one or two of the most widely used components, even at large scale. Finally, in a context where developing tools for monitoring diversity is considered as a high priority worldwide, the strong reproducibility of the relationships between diversity indices we observed offers a basis for discussion of the feasibility and relevance of proposing a general shortlist of indices for monitoring diversity at different management scales. 


\section{Introduction}

Species diversity has been assessed on the basis of a wide range of indices (see Magurran 2004). Although each of these indices was initially expected to provide complementary insights on species diversity, their proliferation has mainly resulted in increasing confusion, and ultimately limits their use for both theoretical and field studies (Cousins 1991, Ricotta 2005). Species richness, and to a lesser extent evenness, still play a dominant role as surrogates for diversity in many studies in ecology (Gaston and Spicer 1998, Magurran 2004). This strategy, which implicitly assumes that all the aspects of diversity are correlated in one or two dimensions, seems not to be supported by recent theoretical (Purvis and Hector 2000) and experimental studies (Ma 2005, Wilsey et al. 2005, Bock et al. 2007, Gonzales-Megias et al. 2007, Mérigot et al. 2007a, Wilsey and Stirling 2007, Heino et al. 2008, Mendes et al., 2008, Chalcraft et al., 2009) which suggest that diversity is a more complex and multidimensional concept than previously thought. This view implies that taking fully into account the complexity of diversity in experiments on ecosystem functioning and in conservation studies requires extension of the range of traditionally used biodiversity concepts and measures (Price 2002, Wilsey et al. 2005).

From a methodological viewpoint, Purvis and Hector (2000) pointed out that "the stronger the correlations (between diversity indices), the more reasonable it will be to reduce multiple measures to a few principal components, to create dimensions of diversity". Wilsey et al. (2005) assumed that the number of complementary dimensions of diversity might vary depending on underlying environmental gradients to which each measure of diversity responds, as well as the scale of measurement. However, to date, whatever the (terrestrial or marine) ecosystem, the degree of reproducibility of the relationships between indices - and the degree of reproducibility of the nature and the number of the components that provide complementary information on species diversity - have been poorly identified. From a practical point of view, this means considering the feasibility of drawing up a general shortlist of diversity indices for properly describing and monitoring the main components of species diversity for a given faunistic or floristic group at different management scales. In the present context of the general increase in anthropogenic activities and global change, drawing up a single list of indices could constitute a preliminary step with a view to working out multiplescale scientific strategies in order to provide effective help to decision makers with regard to the monitoring and conservation of diversity.

In the present work, we investigate the reproducibility of the relationships between multiple diversity indices across areas, years and scales for groundfishes in the Mediterranean Sea. This large marine ecosystem, which constitutes a priority area for conservation (Barcelona Convention 1976) has been exposed, over the last decades, to very strong and rapid changes under the pressure of anthropogenic impact (Caddy et al. 1995, Stergiou et al. 1997) and global change (Bethoux et al. 1990, Bianchi and Morri 2000). However, as in most of the other large marine ecosystems, the lack of knowledge on (1) the relationships between the main diversity indices and (2) the reproducibility of their relationships across areas and scales seriously limit our ability to grasp and monitor the full complexity of Mediterranean marine diversity and thus to properly assess the response of marine communities in the face of natural and anthropogenic factors.

Our work is partly based on a recently conceived approach (Mérigot et al. 2007a) that simultaneously analyses 11 widely used diversity indices related to four major aspects (or components) of species diversity (species richness, rarity, evenness and species taxonomy). However, our study is complementary to and expands upon those of previous works that 
simultaneously analysed the relationships between multiple diversity indices in several ways. Firstly, in contrast to most of the terrestrial studies that analyzed species diversity through multiple indices (Beisel et al. 1998, Wilsey et al. 2005, Bock et al. 2007, Chalcraft et al. 2009, Dickson and Wilsey 2009), our work is one of the few to include measurements that take explicitly into account the degree of differences between species (here using indices of taxonomic diversity; see however Heino et al. 2008 on aquatic insects). Secondly, in comparison with the rare previous marine studies that explicitly analyzed the multicomponent structure of species diversity, we propose the first analysis of fish diversity based on standardized and high resolution data to be undertaken at such a broad geographic scale. Previous studies that analysed the multicomponent aspect of the diversity of groundfishes were restricted to a regional scale (<500 km of coastline): the Gulf of Lions (Mérigot et al. 2007a, 149 hauls) and the east coast of Corsica (Mérigot et al. 2007b, 79 hauls). Here, we have greatly extended the size of the study zone $(\sim 20000 \mathrm{~km}$ of coastline), the data set analysed (2404 standardized hauls), and the scales considered (region, biogeographical zones, basin and the whole northern Mediterranean). Thirdly, and more importantly, analysing the relationships between multiple diversity indices is one thing, but analysing the reproducibility of these relationships is another. To our knowledge, whatever the ecosystem, no study has directly investigated the reproducibility of the empirical relationships between multiple diversity indices across both areas and scales. In this respect, this work offers a first opportunity to determine whether there is a general pattern of redundancy or complementarity in diversity measures that holds good across areas and scales. This provides a preliminary basis for discussing the feasibility and relevance of proposing a general shortlist of complementary indices for monitoring diversity at different management scales.

\section{Materials and methods}

\section{Study zones and sampling design}

We analysed data collected from annual bottom trawl surveys performed in spring (MayJune) from 1996 to 1999 over the continental shelves (10 to $200 \mathrm{~m}$ depth) of the northern Mediterranean Sea within the framework of the MEDITS project (Bertrand et al. 2002).

Due to its very large size - more than $20000 \mathrm{~km}$ of coastline shared between several countries from the Strait of Gibraltar to the Strait of Dardanelles, ranging from 36.3 to $45.7^{\circ}$ $\mathrm{N}$, and $5.3^{\circ} \mathrm{W}$ to $28^{\circ} \mathrm{E}-$ the study zone has been divided into operative sub-areas. These operative sub-areas were defined by the scientific teams in charge of the surveys on the basis of both sampling and administrative constraints and knowledge of environmental and anthropogenic characteristics of the surveyed areas (see Bertrand et al. 2002 and Gaertner et al. 2007 for further details on the definition of these areas). In each sub-area, a stratified random-sampling design based on bathymetric strata (10-50 m, 51-100 m, 101-200 m) was applied. All the sub-areas and strata were sampled in each of the four surveys performed from 1996 to 1999. The sampling procedures of these surveys were standardised according to a common protocol including the use of the same gear and the same sampling strategy for the whole zone studied and during the whole period studied. The standard device was a bottom trawl (GOC 73) with 20-mm cod-end mesh size (stretched mesh). The vertical opening of the gear was about $2 \mathrm{~m}$, and its wing spread about $18 \mathrm{~m}$. All the tows were performed during daylight hours. Speed on the ground and duration of the tows were standardized at 3 knots and 30 minutes respectively. Otherwise, information recorded by an underwater Scanmar system - to control the trawl geometry (horizontal and vertical openings, 
contact with the bottom) - partly limited our "blindness" and allowed us to exclude the tows that had not been properly carried out.

For the present study, the relationships between the indices has been analyzed at four spatial scales (regions, basins, biogeographical zones and the whole northern part of the Mediterranean Sea, Fig.1), using the tow as the spatial grain. Thus, a single tow always serves as the unit of analysis (i.e. the diversity measures are derived for each tow) while the size of the studied area (extent) varies from one scale to another. Using the tow with a surface of $\sim 0.5 \mathrm{~km}^{2}$ as the fixed grain is relevant with regard to biological and ecological traits of demersal fishes (such as their degree of mobility) on the one hand and to the homogeneity/heterogeneity of the habitat on the other hand. The definitions of regions, biogeographical zones and basins correspond to those adopted in Gaertner et al. (2007 see references herein for further details on the biological and geomorphological characteristics for any or part of the studied zone). To limit the length of the ms, and to avoid displaying the same results several times, we have illustrated the multi-component structure of groundfish diversity through a limited number of cases. At regional scale, we have illustrated the multi-component structure of groundfish diversity by the analysis of data from the Gulf of Lions (area 4 on Fig. 1) and the South West Adriatic area (area 16 on Fig. 1). These two areas belong to 2 different biogeographical zones (Iberian-Lion zone and Adriatic Sea) and thus to two different topographical basins (western and eastern basins). They also showed contrasting situations in terms of species richness and beta diversity levels. The Gulf of Lions is both one of the most species-rich regions and one of the weakest regions in terms of beta-diversity of the whole study zone, while the South West Adriatic is characterized by the opposite pattern (see Gaertner et al. 2007). In addition, while all the regions studied were sampled with quite a good effort (a large majority of them were sampled by more than 50 tows) the Gulf of Lions and the South West Adriatic have been the focus of an additional sampling effort (i.e. 199 and 203 trawls for the Gulf of Lions and the South West Adriatic area respectively). Thus, choosing these two areas to illustrate our results at regional scale also allowed us to investigate the empirical relationships between indices on the basis of a large number of stations (limiting any problem of instability, which may often occur when correlations are computed on the basis of only a few observations). At the scale of biogeographical zone, the multi-component structure of groundfish diversity is analysed through data from the Tyrrhenian (areas 5 to 11 on Fig. 1) and the Adriatic seas (areas 16 to 20 on Fig. 1). These two biogeographical zones belong to 2 different topographical basins and also showed contrasting situations notably in terms of species richness and beta diversity values (see Gaertner et al. 2007). At basin scale, we analysed data from the northern part of the two Mediterranean topographical basins: western (areas 1 to 11 on Fig. 1) and eastern basins (areas 12 to 23 on Fig. 1).

Several vessels were used simultaneously in order to complete the sampling of the whole zone during a short period of the year and the work at sea was divided up between several teams. Despite the strong effort of sampling standardization, possible variability of accuracy in sampling identification between the different teams could affect the analysis of spatial patterns of species diversity. In the present work, we have taken several precautions in order to limit the significance of such a bias. First, we have restricted our analysis to the groundfishes because they appeared to be easier to identify at species level than other benthic faunistic groups such as crustaceans and cephalopods. Fish was the main target group of the MEDITS surveys, and several specialists in fish identification were on board during the surveys in each of the regions studied. Second, we have defined the list of fish species properly sampled in each area. This stage notably led us to only consider benthos associated fishes and thus pelagic species were never taken into account in the analyses. In addition, in a very limited number of cases, a given species clearly identified in one region might be confused with another species in another region. To limit such a bias, several species of a single genus that could have been potentially confused by some teams at regional scale have been clustered (Appendix A). Third, we have restricted our analysis to a 
short period of time to limit the influence of possible variations in sampling procedures during the course of the study. A deep analysis of the data led us to restrict our study to 4 surveys (1996 to 1999). These data have been subjected to a strong - and extensive - validation stage by all the MEDITS teams and they appeared to be the most standardized at the scale of the whole study area.

\section{Diversity indices and statistical analyses}

Following the same methodological approach as that proposed by Mérigot et al. (2007a), we investigated the diversity patterns of demersal fish assemblages through the simultaneous analysis of 11 indices representing four major components of diversity (1) species richness, (2) rarity, (3) evenness and (4) species taxonomy. These 11 indices have been chosen according to their theoretical properties and the nature of the available data (see Mérigot et al. 2007a, b for detailed explanation).

In summary, we first analysed the number of species by means of two indices : i) the number of species per tow as a measure of species density $S$ and ii) Margalef's species richness index $D_{\mathrm{mg}}$ (Margalef 1958) (Table 1). Because species richness is highly sensitive to sampling effort (Gaston and Spicer 1998), only the tows with close swept areas have been included in the analyses $(n=2404$ at the whole MEDITS scale; mean \pm Sd : $0.045 \pm 0.003$ $\mathrm{km}^{2}$ ). We checked that swept area variation within the selected tows did not affect values in species richness through a $\mathrm{Chi}^{2}$ test of independence $(P>0.05)$. Secondly, we considered rarity by means of a rarity index which corresponds to the number of rare species in each sample (or tow), with rare species occurring in less than $5 \%$ of the tows for the whole MEDITS zone (Appendix A),

Thirdly, we analysed the evenness component of diversity by mean of i) the Heip's evenness index $E_{\text {Heip }}$ (Heip 1974) and ii) the $d$ Berger Parker index (Berger and Parker 1970). These two indices are complementary as they differ in sensitivity to changes in evenness of rare or dominant species respectively (Smith and Wilson 1996, Ricotta et al. 2001). We also computed two heterogeneous indices, the Shannon index $H^{\prime}$ (Shannon and Weaver 1949) and the Simpson concentration $D$ index (Simpson 1949), which combine both the number of species and evenness components in a single value. Although they are not focused on a single diversity component we computed heterogeneous indices both because they are implicated in one of the rare ecological theories based on the relationships between diversity indices (see Caswell 1976, Stirling and Wilsey 2001), and because they are extensively used in the literature, providing a reference base to better compare our results with those of other studies.

Fourthly, we computed four taxonomic indices proposed by Warwick and Clarke (Table 1) that quantify the taxonomic diversity of a faunal assemblage in terms of average distance of all pairs of individuals (or species) in a sample by tracing these distances through a Linnaean taxonomic tree. These indices are complementary because they differ in i) their sensitivity with regard to dominant species ( $\Delta$ versus $\Delta^{*}$, Warwick and Clarke 1995, Clarke and Warwick 1998), ii) the nature of the data used $\left(\Delta, \Delta^{*}\right.$ based on abundance data versus $\Delta^{+}, \Lambda^{+}$ based on presence-absence data, Clarke and Warwick 1998, 2001). We adopted the simplest form of $\omega_{i j}$ with equal step-lengths between each successive taxonomic level, setting the $\omega_{i j}$ at 100 for two species connected at the highest (taxonomically coarsest) possible level (Clarke and Warwick 1999).

A 2-stage procedure was carried out to identify both redundant and complementary descriptors of diversity. In a first stage, we analysed the multicomponent structure of fish diversity through the use of principal component analyses (PCA). Because atypical values of some descriptors could strongly influence the correlation coefficients based on abundance data, we carried out a PCA based on the Spearman's rank correlation matrix (Jolliffe 1986). This consists in computing a classical PCA on the ranks of diversity indices values. The 
projection of diversity indices onto the factorial axes of the PCA allows access graphically to an overall perception of the correlations between the indices. However, it does not represent the exact reality of these correlations, but only a less distorted description of them. Consequently, in a second stage we completed the procedure by an in-depth analysis of the Spearman rank correlation matrix which gives the pairwise correlations values between all the indices studied. The Spearman's correlations matrix produced less accessible but more precise information on the correlations between the indices studied. This whole procedure (PCA and Spearman correlation matrix) was conducted separately for each of the years, areas and scales considered to investigate the "reproducibility" of the relationships between the diversity indices. All the indices and statistical analyses were performed using R software (version 2.9.1, R development Core Team, 2009). Detailed information on the indices and method adopted (PCA and Spearman correlation) is provided in Mérigot et al. (2007a).

\section{Results}

We used the analysis of the data from the Gulf of Lions as a reference base for describing the multi-component aspect of groundfish diversity. For clarity and because PCA is only used as a preliminary step to facilitate the visualization of the main groups of complementary indices, the detailed analysis of the PCA is restricted to the first two components. All evenness indices $\left(E_{\text {Heip }}\right.$ and $\left.1 / d\right)$, the two heterogeneous indices $\left(H^{\prime}\right.$ and $\left.1-D\right)$ and one of the taxonomic diversity indices $(\Delta)$ strongly load on the first principal component $(47.1 \%$, Fig. $2 a)$. The second principal component $(17.84 \%)$ was mainly explained by the two indices focused on the number of species ( $S$ and $D_{\mathrm{mg}}$ ). In contrast, the projection of the three other taxonomic indices $\left(\Delta^{*}, \Delta^{+}\right.$, and $\left.\Lambda^{+}\right)$and rarity clearly showed that none of these indices contributed to the first two principal components. This means that these four indices provided complementary information to those that strongly load the first two axes. The weak Spearman's correlations observed between these four indices and each of the other ones (Table 2a) confirmed this result. In addition, Table $2 \mathrm{a}$ also showed that $\Delta^{*}, \Delta^{+}$, and $\Lambda^{+}$and rarity are weakly redundant with regard to each other. Each of these four indices mainly provided complementary insights on groundfish species diversity in the Gulf of Lions.

Correlations between indices may appear to be significant, even for low correlations values (e.g. between $S$ and $H^{\prime}$, where Spearman coefficient $=0.33$ but $P<0.05$ ). This mainly results from the high number of observations that increase the power of the statistical tests. However, here the question is not to assess whether the correlation between two indices is significantly different from zero (information provided by $p$-values) but rather which part of the information they provide is roughly complementary (information provided by the value of the corresponding Spearman rank correlation coefficients). In this context, we assume in the present work that a Spearman rank correlation coefficient $<0.5$ means that an important part of the information provided by the two corresponding indices is complementary, keeping the two indices in the analysis of diversity patterns. Bearing in mind this reasoning, the simultaneous analysis of PCA and Spearman correlation coefficients provides a basis for roughly grouping the 11 species diversity descriptors studied into 6 complementary components of diversity: (1) number of species ( $S$ and $D_{\mathrm{mg}}$ ), (2) evenness $\left(E_{\text {Heip }}, 1 / d\right)$, heterogeneous indices $\left(H^{\prime}, 1-D\right)$ and $\Delta$, (3) rarity and each of the three other measures of taxonomy : (4) $\Delta^{*}$, (5) $\Delta^{+}$, and (6) $\Lambda^{+}$.

The similar procedure (i.e. the combination of PCA and Spearman's correlations matrix) carried out separately on the other areas and scales considered provided very similar results. This strong reproducibility is observed for (1) the decomposition of the inertia along the main 
PCA axes (Table 3), (2) the projection of the diversity indices onto the first principal components (Fig. $2 \mathrm{~b}$ to $2 \mathrm{~g}$ ), and more importantly (3) the Spearman correlations between all the indices studied (Tables $2 \mathrm{~b}$ to $2 \mathrm{~g}$ ). In addition, assessment of temporal variation showed that the multi-component structure of species diversity is also highly reproducible from year to year (see an illustration in Fig. 3). The corresponding Spearman correlation matrices on the entire data set for each year separately (not shown) confirm the strong temporal reproducibility of the relationships between indices. In each case, axis 1 is still mainly explained by the strong association between $\Delta$, evenness indices $\left(E_{\text {Heip }}, 1 / d\right)$ and heterogeneous indices $\left(H^{\prime}, 1-D\right)$ while the second axis is mainly associated with the two indices of species richness $\left(S\right.$ and $D_{\mathrm{mg}}$ ). In most cases, $\Delta^{+}$also contributes to the construction of axis 2 but Spearman rank correlation shows that correlations between $\Delta^{+}$and the species richness indices ( $S$ and $D_{\mathrm{mg}}$ ) are still weak (as for the Gulf of Lions). In addition, while $D_{\mathrm{mg}}$ always appears to be mainly correlated with $S$, it could also be secondarily associated with $H^{\prime}$, and to a lesser extent with some of the indices that explain axis 1 . Otherwise, as for the analysis of the Gulf of Lions, rarity and the three other taxonomic indices are poorly represented on the first factorial plane. Finally, whatever the area or year considered, Spearman rank correlation confirmed that $\Delta^{*}, \Delta^{+}, \Lambda^{+}$and rarity are weakly correlated with evenness indices on the one hand and with estimates of species richness on the other hand. It also confirmed that correlations between $\Delta^{*}, \Delta^{+}, \Lambda^{+}$, and rarity are usually low. The main exception occurred between $\Delta^{+}$and $\Lambda^{+}$for the South West Adriatic region $(r=-$ $0.65)$.

In short, both the comparisons between the different years for a given area (see an illustration for the whole study zone in Fig.3), between the different areas for a given scale (i.e. Gulf of Lions vs South West Adriatic; Tyrrhenian vs Adriatic Sea, Western vs Eastern basin) and between the different scales (region, biogeographical zone, basin and the whole North Mediterranean Sea) showed a high degree of reproducibility in the empirical relationships of the diversity indices studied. This result notably shows that the general relationships observed between diversity indices of groundfishes seems to be reproducible for situations characterized by contrasting species richness and beta-diversity values (see comparison between the Gulf of Lions and the South West Adriatic area). This strong homogeneity is accompanied by very limited fluctuations.

\section{Discussion}

\section{Multi-component structure of species diversity}

From a theoretical point of view, the possible meaning of the relationships between diversity indices in term of ecosystem functioning has been investigated through the analysis of a very limited number of indices, mainly species richness, evenness and heterogeneous indices. Stirling and Wilsey (2001) proposed the use of the relationship between these three kinds of descriptors to define whether species diversity is (1) regulated by dispersal and migration, or (2) structured more by other factors such as biotic interactions (e.g. competition, predation) or effects of the environment. This rationale was based on Caswell's neutral model (Caswell 1976) which makes explicit predictions that richness, evenness and heterogeneous index will be positively and strongly correlated if dispersal and migration are the single structuring factor. In our study, the correlation between richness and evenness always remained very weak. According to the above-mentioned theory, this result suggests that groundfish diversity is not solely regulated by dispersal or migration but that inter-specific interactions and/or effects of the environment might be also involved. This conclusion provides little new insight on the determinism of groundfish diversity and could also seem to be trivial for numerous 
other taxa. However, a non-exhaustive analysis of the literature showed contrasting results both within and between taxa (vertebrates, invertebrates) and ecosystems (terrestrial or marine). The relationship between species richness and evenness may be negative (Stirling and Wilsey 2001, Wilsey et al. 2005, Manier and Hobbs 2006, Bock et al. 2007, Wilsey and Stirling 2007, Symonds and Johnson 2008), positive (Stirling and Wilsey 2001, Manier and Hobbs 2006) or non-apparent (Ma 2005, Bock et al. 2007). In this context, we agree with Symonds and Johnson (2008) who claimed that "a challenge for ecologists is to better catalog the way in which species richness and evenness co-vary across a wider range of scales, species, and habitat". Our study clearly adds a brick to this wall. Indeed, for Mediterranean groundfish assemblages, we clearly show that a very weak - quasi nonapparent - relationship between species richness and evenness was consistent across the various scales and environmental conditions studied.

From a practical viewpoint, our results raise the question of the extensive use of heterogeneous indices that combine both the number of species and evenness components in a single value. We have shown that the two most popular indices of this family (i.e. Shannon and Simpson indices) appeared to be strongly correlated to evenness but weakly to the number of species. This result extended to a wide range of scales and areas those that have been previously observed for Mediterranean groundfishes in two small regions (Mérigot et al. 2007a, b). It is also consistent with results observed for other marine communities (see Beisel et al. 1998, on stream invertebrates or Gaertner et al. 2008, on open-ocean pelagic fishes). Thus, in spite of their expected properties (that to a large extent account for their popularity in monitoring and conservation studies), the use of heterogeneous indices in field studies might fail to really encapsulate both the species richness and evenness components of diversity of marine communities. More generally, the independence between the number of species and evenness sheds doubt on the extensive use of heterogeneous indices - that combine these 2 components in a single value - in the monitoring of species diversity. This problem is particularly striking in a context where some empirical studies suggest that species number and evenness are related to different responses to environmental factors (Stirling and Wilsey 2001, Ma 2005, Reitalu et al. 2009), affecting in different and possibly opposite directions the variation of the heterogeneous index (Buzas and Hayek 1996).

In addition, our results also clearly confirm for each of the scales and areas studied the need to complement the use of species richness and evenness by several other indices, as shown in both terrestrial and marine ecosystems (e.g. Price 2002, Wilsey et al. 2005, Mérigot et al. $2007 a, b$, Heino et al. 2008). Most of the indices of taxonomic diversity considered in our study $\left(\Delta^{*}, \Delta^{+}\right.$, and $\left.\Lambda^{+}\right)$might provide complementary information on groundfish diversity. Of course, definition of functional traits of fish species would be more suitable as a basis for analysing functional structure than taxonomic distance. Unfortunately, relevant knowledge of functional aspects for all the species of a given assemblage are still rarely available in studies dedicated to fishes (see however Mouillot et al. 2007). The building of databases on functional traits of fishes is usually very difficult, particularly at large scale (such as the whole northern Mediterranean Sea). In such a situation, testing the behaviour of the taxonomic diversity indices in comparison to the most traditional components is particularly important. Several authors suggest that taxonomic structure is related to the structure of functional groups in species assemblages (Warwick and Clarke, 1998, von Euler and Svensson, 2001, Heino 2008). In any case, data on functional traits - when they exist - could be included in the approach adopted in the present work.

\section{Reproducibility of the multi-component structure of groundfish diversity}


We found strong reproducibility of the relationships between diversity indices and components across years, areas and scales. The reproducibility of the relationships between all the indices we observed between areas for a given spatial scale was consistent with the hypothesis offered by Wilsey et al. (2005) on terrestrial plants of expected similar patterns of variation in species diversity when comparing areas characterized by similar species pools, common underlying environmental gradients and comparable spatial scales with respect to focus and extent. In contrast, our multi-scale comparative analysis did not find the expected difference in patterns of variation in species diversity when the scale of observation varies (Wilsey et al. 2005). In some cases, the reproducibility observed between scales might be partly explained by the fact that the subsets of the data sets compared are not completely independent (e.g. when comparing Gulf of Lions and Iberian-Lions zone). However, we also observe the same between-scale reproducibility of the relationships even when independent data sets are compared (e.g. Gulf of Lions vs Adriatic Sea or Tyrrhenian Sea vs eastern basin, etc.). The reproducibility of the multi-component structure of groundfish diversity shows that the relationship between the indices and components studied is neither sitespecific nor scale-specific. In addition the number and the nature of the complementary components we observed is very similar to previous results provided for Mediterranean groundfishes at regional scales, using the same methodology, for both different patterns of dominance (Mérigot et al. 2007a) and different bathymetric strata (Mérigot et al. 2007b). It is also very similar to those observed for pelagic fishes (through underwater visual censuses around drifting fish aggregating devices) in the Indian Ocean (Gaertner et al. 2008). This strong reproducibility supports the emergence of a general pattern in the multi-component structure of fish diversity. From a practical viewpoint, it could advocate the selection of a single set of diversity indices for monitoring fish diversity at different management scales.

\section{Towards the development of a shortlist of species diversity indices ?}

The strong reproducibility of the multi-component aspect of species diversity we observed in this study is a preliminary, but important, step towards the constitution of a shortlist of complementary diversity indices with a view to monitoring and managing fishes in the future on the basis of a single set of indices. When a diversity component can be described by several redundant indices, we select the index that is the most intuitively simple to understand and easiest to calculate. For instance, for monitoring the component dedicated to the number of species, species richness $(S)$ might be preferred to Margalef $\left(D_{\mathrm{mg}}\right)$. Indeed, species richness is more popular (favouring comparison between studies) and easier to compute (no need to assess the total abundance); it also appeared to be weakly correlated with all the others indices. In contrast, our results show that information provided by $D_{m g}$ is less clear. $D_{m g}$ is the only index that could be associated with two complementary components (i.e. species richness and Shannon index from components 1 and 2 respectively). Otherwise, the Berger-Parker index (1/d), which is simple to understand and easy to measure (the identities of species other than the most abundant species do not need to be determined), might be a good candidate for summarizing the evenness component of diversity (Mérigot et al. 2007a, Gaertner et al. 2008). Following this reasoning, we can propose simultaneously using 1) $S$, 2) $1 / d$, 3) $\Delta^{*}$, 4) $\Delta^{+}$, 5) $\Lambda^{+}$and 6) rarity as a preliminary shortlist of indices for monitoring the diversity of Mediterranean groundfishes.

The general approach we propose has the particular advantage of allowing the selection of a set of complementary indices according to both their theoretical properties in a preliminary stage (selection of the indices initially computed) and their empirical relationships in a secondary stage (definition of which index will be kept as a proxy of each complementary component on the basis of the results of the analyses). However, the rationale of the choice of a specific index is limited by the fact that each index has desirable properties, but also specific drawbacks. For instance, on the one hand, species richness is very sensitive to 
variation in sampling design (Gaston and Spicer 1998, Magurran 2004). In addition, it now appears difficult to accurately estimate the true number of species in a study area (Margules and Pressey 2000), as has been shown in particular for the Mediterranean groundfish communities (Gaertner et al. 2007). On the other hand, in our study most of the information provided by species richness is different from that given by the other indices studied. Moreover, this descriptor has the additional advantage of being easy to understand, extensively used for theoretical studies and very familiar to decision-makers. Consequently, it can be still considered as a useful tool for communication on biodiversity conservation and ecosystem functions. Because no index is perfect, numerous other examples could have been provided to highlight additional problems encountered with the other indices (see notably Magurran 2004, Bhat and Magurran 2006). Of course, our approach cannot improve the specific properties and make good the limitations of each type of index. However, it does offer a basis for grasping more fully the complexity of species diversity, by basing the analysis on a set of indices which have properties and limitations which are different and possibly complementary.

Despite the strong reproducibility we observed both within this study and in comparison with the previous studies following the same approach (notably Gaertner et al. 2008 for pelagic fishes in the Indian Ocean), the preliminary shortlist we propose cannot be considered as a universal one for describing fish diversity elsewhere in the world. Firstly, even when restricted to the fish community, the present approach would need to be applied to a greater range of ecosystems in order to determine to what extent the relationships we observed may be generalized. Secondly, the selection of the initial components and descriptors to be used to describe species diversity should partly depend on both the objectives of the study and the nature of the available data (presence-absence vs abundance data, knowledge of some biological traits, etc.). When relevant data is available, the interest of adding indices related to other diversity components (notably those describing functional diversity, see for instance Petchey and Gaston 2006 or Villéger et al., 2008) should be assessed. Thirdly, proposing once and for all a definitive shortlist of indices that appear to be complementary through the analysis of past and present data could fail to catch the full complexity of species diversity in the future if disturbances alter the responses and possibly the complementarity/redundancy between some indices. Consequently, while using a shortlist of indices might be relevant for monitoring purposes, the composition of this list should be regularly re-assessed in the light of the responses of the main complementary diversity components facing anthropogenic pressure.

In conclusion, the multi-component aspect of species biodiversity, and its strong reproducibility, implies that we cannot continue to base the priorities for global biodiversity conservation solely on the amount of biological diversity (especially on the basis of one or two indices), as has traditionally been done. Given that different indices describe different components of biodiversity and are not strongly related, multiple indices should be considered in any study describing fish biodiversity whatever the scale of study. The threestage approach we adopted - (1) selection of a set of indices according to theoretical properties, the goals of each study and the specific context including data availability, (2) identification of components providing complementary insight into diversity in the field, and (3) analysis of the reproducibility of the multicomponent aspect of species diversity across different situations and scales - is flexible and easily transferable to a wide range of taxa and contexts. A further question that needs to be raised is: are all complementary components of species diversity equally important for the purposes of understanding ecosystem functioning and sustaining conservation? Identifying which of the complementary facets of species diversity should be considered as a priority for both ecosystem functioning and conservation planning is one of the next major challenges for ecologists for both marine and terrestrial ecosystems. It will require improvement of our knowledge on the link between diversity and 
ecosystem functioning on the one hand and the taking into account of socio-economic constraints on the other.

\section{Acknowledgements}

This study was carried out within the framework of the "Species assemblages and diversity" working group of the International MEDITS programme. We wish to thank all participants in the surveys conducted along the coasts of the North Mediterranean Sea within the MEDITS programme. We also thank Michael Paul for correcting of the English of the paper.

\section{Literature cited}

Beisel, J.N. et al. 1998. Stream community structure in relation to spatial variation: The influence of mesohabitat characteristics. Hydrobiologia 389: 73-88.

Berger, W.H. and Parker F.L. 1970. Diversity of planktonic foraminifera in deep-sea sediments. Science 168: 1345-1347.

Bertrand, J.A. et al. 2002. The general specifications of the MEDITS surveys. Sci. Mar. 66: 917.

Bethoux, J.P. et al. 1990. Warming trend in the western Mediterranean deep water. Nature 347: 660-662.

Bianchi, C.N. and Morri, C. 2000. Marine biodiversity of the Mediterranean Sea: Situation, problems and prospects for future research. Mar. Poll. Bull. 40: 367-376.

Bhat, A. and Magurran, A.E. 2006. Taxonomic distinctness in a linear system: a test using a tropical freshwater fish assemblage. Ecography 29: 104-110.

Bock, C.E. et al. 2007. Relationships between species richness, evenness, and abundance in a southwestern Savanna. Ecology 88: 1322-1327.

Buzas M.A. and Hayek L.A.C. 1996. On richness and evenness within and between communities. Paleobiology 31(2):199-220

Caddy, J.F. et al. 1995. Productivity estimates for the Mediterranean: evidence of accelerating ecological change. Ocean Coast. Manage. 26: 1-18.

Caswell, H. 1976. Community structure: a neutral model analysis. Ecol. Monogr. 46: 327354.

Chalcraft, D.R et al. 2009. The relationship between productivity and multiple aspects of biodiversity in six grassland communities. Biodivers. Conserv.18: 91-104.

Clarke, K.R and Warwick R.M. 1998. A taxonomic distinctness index and its statistical properties. J. Applied Ecol. 35: 523-531.

Clarke, K.R. and Warwick R.M. 1999. The taxonomic distinctness measure of biodiversity: weighting of step lengths between hierarchical levels. Mar. Ecol. Prog. Ser. 184: 21-29.

Clarke K.R. and Warwick R.M. 2001. A further biodiversity index applicable to species lists: variation in taxonomic distinctness. Mar. Ecol. Prog. Ser. 216: 265-278.

Cousins, S.H. 1991 Species-Diversity Measurement - Choosing the Right Index. TREE. 6: 190-192.

Dickson, T.L. and Wilsey, B.J. 2009. Biodiversity and tallgrass prairie decomposition: the relative importance of species identity, evenness, richness, and micro-topography. Plant Ecol. 201: 639-649.

Gaertner, J.C. et al. 2007. Spatial pattern in species richness of demersal fish assemblages on the continental shelf of the northern Mediterranean Sea: a multiscale analysis. Mar. Ecol. Prog. Ser. 341: 191-203.

Gaertner, J.C. et al. 2008. Visual censuses around drifting fish aggregating devices (FADs): a new approach for assessing the diversity of fish in open-ocean waters. Mar. Ecol. Prog. Ser. 366: $175-186$. 
Gaston, K.J. and Spicer, V.I. 1998. Biodiversity: an introduction. Blackwell Science, Oxford. Gonzalez-Megias, A. et al. 2007. Diversity-habitat heterogeneity relationship at different spatial and temporal scales. Ecography 30: 31-41.

Heip, C. 1974. A new index measuring evenness. J. Mar. Biol. Assoc. U.K. 54: 555-557.

Heino, J. 2008. Patterns of functional biodiversity and function-environment relationships in lake littoral macroinvertebrates. Limnol. Oceanogr. 53: 1446-1455.

Heino, J. et al. 2008. Weak relationships between landscape characteristics and multiple facets of stream macroinvertebrate biodiversity in a boreal drainage basin. Landscape Ecol. 23: 417-426.

Jolliffe I.T., 1986. Principal Component Analysis. Springer-Verlag, 271 pp.

Ma, M. 2005. Species richness vs evenness: independent relationship and different responses to edaphic factors. Oikos 111: 192-198.

Magurran, A.E. 2004. Measuring biological diversity. Blackwell Science, Oxford.

Manier, D.J. and Hobbs, N.T. 2006. Large herbivores influence the composition and diversity of shrub-steppe communities in the Rocky Mountains, USA. Oecologia 146: 641-651.

Margalef, R. 1958. Information theory in ecology. General Systems 3: 36-71.

Margules, C.R. and Pressey, R.L. 2000. Systematic conservation planning. Nature 405: 243253.

Mendes, R.S. et al. 2008. A unified index to measure ecological diversity and species rarity. Ecography 31: 450-456.

Mérigot, B. et al. 2007a. The multi-component structuration of the species diversity of groundfish assemblages of the east coast of Corsica (Mediterranean Sea): Variation according to the bathymetric strata. Fish. Res. 88: 120-13.

Mérigot, B. et al. 2007b. A multi-component analysis of species diversity of groundfish assemblages on the continental shelf of the Gulf of Lions (north-western Mediterranean Sea). Estuar. Coast. Shelf. Sci. 73: 123-136.

Mouillot, D. et al. 2007. Limiting similarity, niche filtering and functional diversity in coastal lagoon fish communities. Estuar. Coast. Shelf. Sci. 71: 443-456.

Petchey, O.L. and Gaston, K.J. 2006. Functional diversity: back to basics and looking forward. Ecol. Lett. 9: 741-758.

Price, A.R.G. 2002. Simultaneous 'hotspots' and 'coldspots' of marine biodiversity and implications for global conservation. Mar. Ecol. Prog. Ser. 241: 23-27.

Purvis, A. and Hector, A. 20002 Getting the measure of biodiversity. Nature 405: 212-219.

R Development Core Team, 2009. R: A language and environment for statistical computing. R Foundation for Statistical Computing, Vienna, Austria. ISBN 3-900051-07-0, http://www.Rproject.org.

Reitalu, T. et al. 2009. Small-scale plant species richness and evenness in semi-natural grasslands respond differently to habitat fragmentation. Biol. Conserv. 142: 899-908.

Ricotta, C. 2005. Through the jungle of biological diversity. Acta Biotheoretica 53: 29-38.

Ricotta, C. et al. 2001. On the mutual relatedness of evenness measures. Community Ecology 2: 51-56.

Shannon, C.E. and Weaver, W. 1949. The Mathematical Theory of Communication. University of Illinois, Urbana, Illinois.

Simpson, E.H. 1949. Measurement of diversity. Nature 163: 688.

Smith, B. and Wilson, J.B. 1996. A consumer's guide to evenness indices. Oikos 76: 70-82.

Stergiou, K.I. et al. 1997. The Hellenic seas: physics, chemistry, biology and fisheries. Oceanography and Marine Biology: an annual review 35: 415-538.

Stirling, G. and Wilsey, B. 2001. Empirical relationships between species richness, evenness, and proportional diversity. Am. Nat. 158: 286-299.

Symonds, M.R.E. and Johnson, C.N. 2008. Species richness and evenness in Australian birds. Am. Nat. 171: 480-490.

Villéger, S. et al. 2008. New multidimensional functional diversity indices for a multifaceted framework in functional ecology. Ecology 89: 2290-2301.

von Euler, F. and Svensson, S. 2001. Taxonomic distinctness and species richness as measures of functional structure in bird assemblages. Oecologia 129: 304-311. 
Warwick, R.M. and Clarke, K.R. 1995. New 'biodiversity' measures reveal a decrease in taxonomic distinctness with increasing stress. Mar. Ecol. Prog. Ser. 129: 301-305.

Warwick, R.M. and Clarke, K.R. 1998. Taxonomic distinctness and environmental assessment. J. Applied Ecol. 35: 532-543.

Wilsey, B. and Stirling, G. 2007. Species richness and evenness respond in a different manner to propagule density in developing prairie microcosm communities. Plant Ecol. 190: 259-273.

Wilsey, B.J. et al. 2005. Relationships among indices suggest that richness is an incomplete surrogate for grassland biodiversity. Ecology 86: 1178-1184.

\section{Figures}

Fig 1.

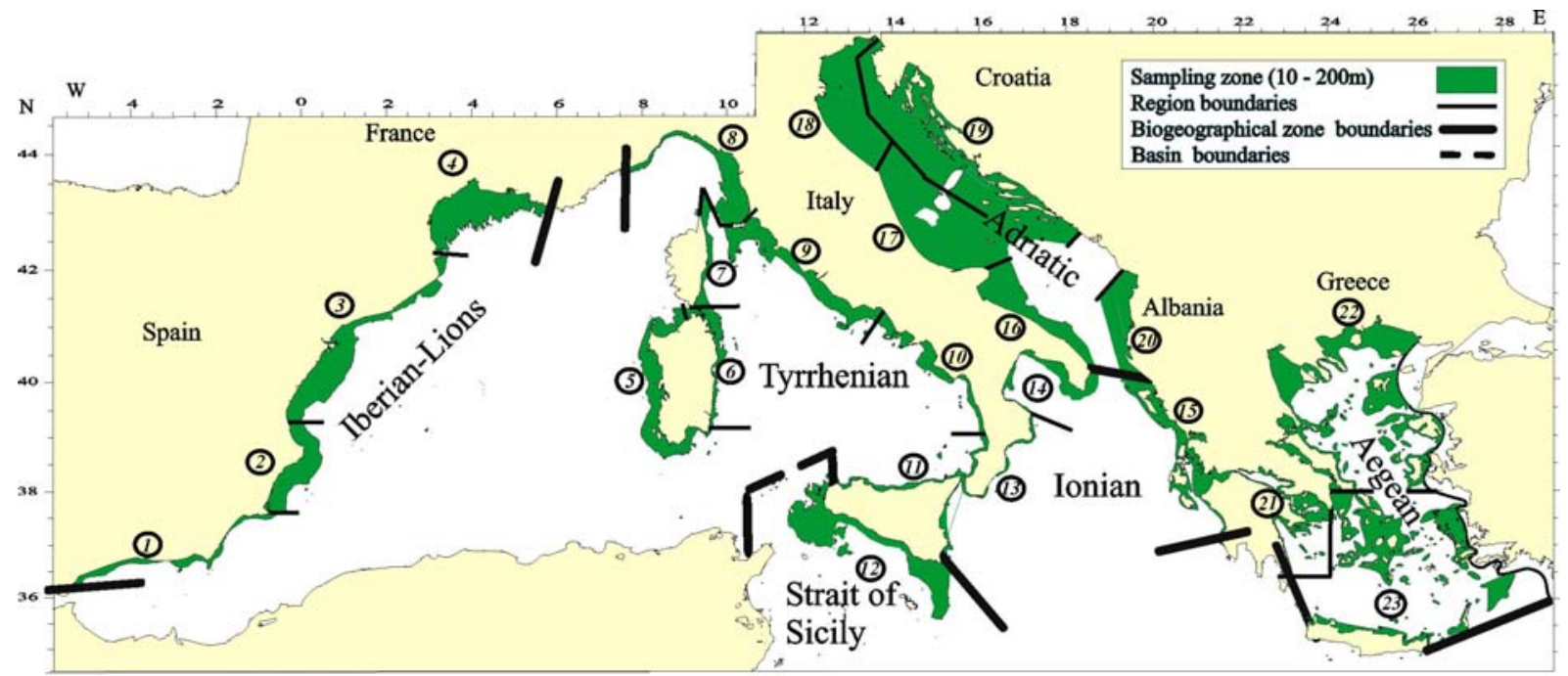

Fig. 1 Map of the area studied with boundaries of the spatial units.

Gaertner et al. 
Fig. 2
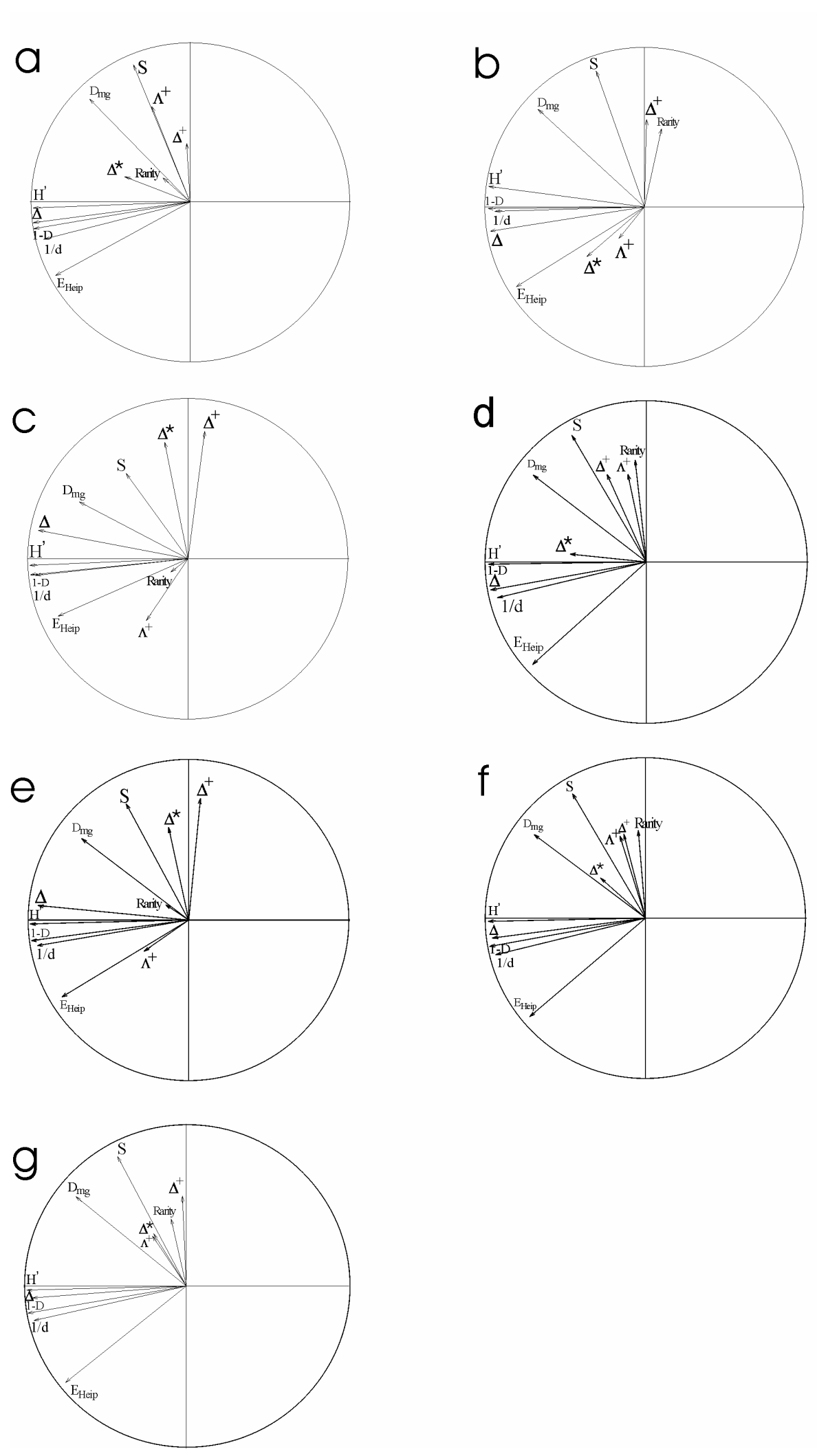

Gaertner et al.

14 
Fig. 2 Projection of the diversity indices onto the first factorial plan of PCA (axis 1: horizontal, axis 2: vertical) for a) Gulf of Lions (area 4 on Fig.1), b) South West Adriatic (area 16), c) Tyrrhenian Sea (areas 5 to 11), d) Adriatic Sea (areas 16 to 20), e) Western basin (areas 1 to 11), f) Eastern basin (areas 12 to 23), and g) whole MEDITS scale. Codes of diversity indices are given in Table 1. 
Fig. 3
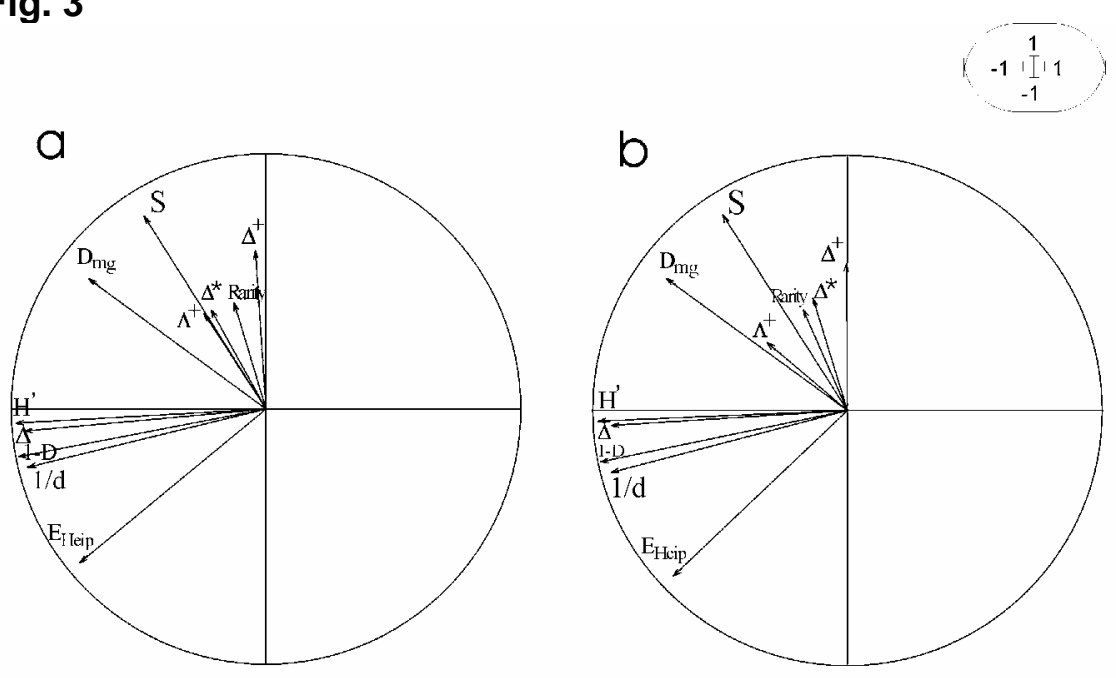

C
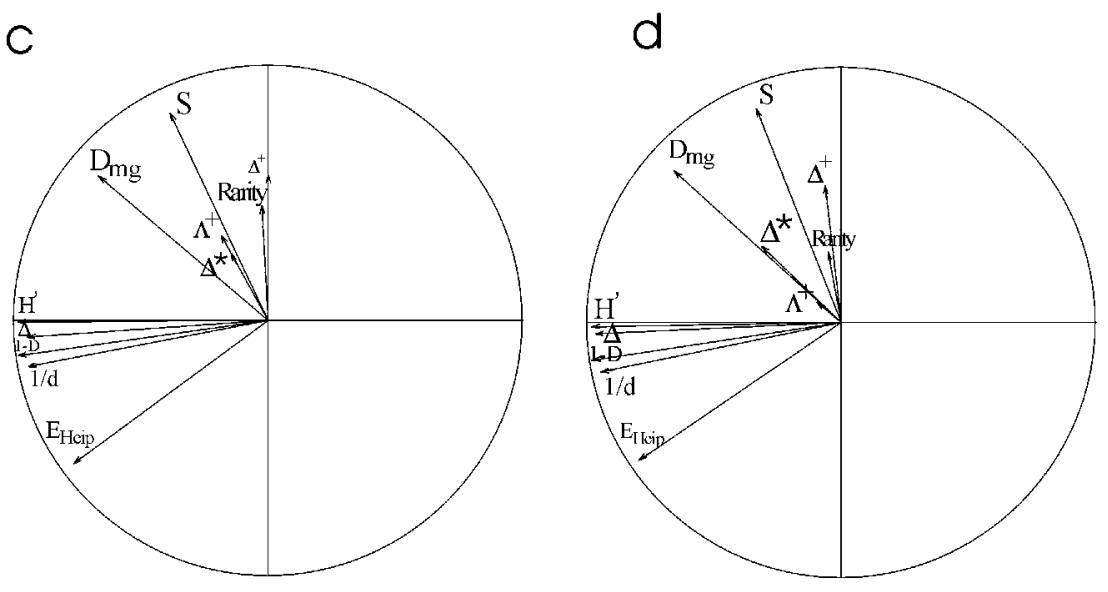

Gaertner et al.

Fig. 3 Projection of the diversity indices onto the first factorial plan of PCA carried out on the whole study zone (axis 1: horizontal, axis 2: vertical) for a) 1996, b) 1997, c) 1998, and d) 1999. Codes of diversity indices are given in Table 1. 
Table 1 Species diversity components and descriptors studied.

\begin{tabular}{llll}
\hline Component & Descriptor name & Formula & Expected properties
\end{tabular}

Number Species density ${ }^{1} \quad S=$ Number of Standardize species

of species species by tows richness per unit area

$\begin{array}{lll}\text { Margalef } \quad D_{\mathrm{mg}}=\frac{(S-1)}{\ln (N)} & \begin{array}{l}\text { Adjusted species } \\ \text { richness by } N\end{array} \quad \text { Margalef (1958) }\end{array}$

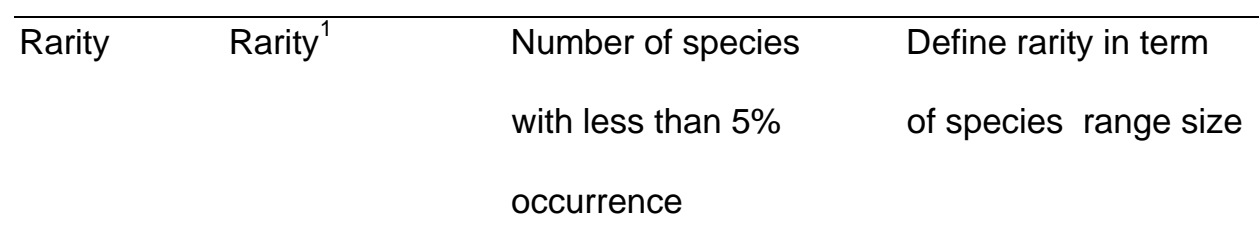

\begin{tabular}{lllll}
\hline Evenness & Heip & $E_{\text {Heip }}=\frac{\exp \left(H^{\prime}\right)-1}{S-1}$ & $\begin{array}{l}\text { Sensitive to } \\
\text { rare species }\end{array}$ & Heip (1974) \\
Berger Parker & $\frac{1}{d}=\frac{N}{N_{\max }}$ & $\begin{array}{l}\text { Sensitive to } \\
\text { dominant species }\end{array}$ & Berger and Parker
\end{tabular}

(1970)

\begin{tabular}{lllll}
$\begin{array}{l}\text { Number of } \\
\text { species }+ \\
\text { evenness }\end{array}$ & Shannon-Wiener & $H^{\prime}=-\sum_{i=1}^{s} p_{i} \log p_{i}$ & $\begin{array}{l}\text { Sensitive to } \\
\text { rare species }\end{array}$ & $\begin{array}{l}\text { Shannon and } \\
\text { Weaver (1949) }\end{array}$ \\
& Simpson diversity & $1-D=1-\left(\sum_{i=1}^{s} p_{i}^{2}\right)$ & $\begin{array}{l}\text { Sensitive to } \\
\text { dominant species }\end{array}$ & Simpson (1949) \\
\hline $\begin{array}{l}\text { Species } \\
\text { taxonomy }\end{array}$ & $\begin{array}{l}\text { Taxonomic } \\
\text { diversity }\end{array}$ & $\Delta=2 \frac{\sum \sum_{i<j} \omega_{i j} X_{i} X_{j}}{N(N-1)}$ & $\begin{array}{l}\text { Extension of D } \\
\text { including taxonomic } \\
\text { relatedness }\end{array}$ & Warwick and Clarke
\end{tabular}


Taxonomic

distinctness

$$
\Delta^{*}=\frac{\sum \sum_{i<j} \omega_{i j} x_{i} X_{j}}{\sum \sum_{i<j} X_{i} X_{j}}
$$

Form of $\Delta$ limiting the influence of species dominance, reflecting pure taxonomic relatedness
Warwick and Clarke

(1995)
Average taxonomic distinctness ${ }^{1}$
Equivalent to $\Delta$ and $\Delta^{*}$ in presence-absence data
Clarke and Warwick $\begin{aligned} & \text { Variation in } \\ & \text { taxonomic } \\ & \text { distinctness }\end{aligned} \quad \Lambda^{+}=2 \frac{\sum \sum_{i<j}\left(\omega_{i j}-\varpi\right)^{2}}{S(S-1)}$
Evenness of the taxonomic level distribution in the taxonomic tree
Clarke and Warwick

(2001)

where $\varpi=\Delta^{+}$

Notes: $x_{i}(i=1, \ldots, S)$ denotes the abundance of the ith species, $N\left(=\Sigma_{i} x_{i}\right)$ is the total number of individuals in the sample, $p_{i}\left(=x_{i} / N\right)$ is the proportion of all individuals belonging to species $i, N_{\max }$ is the number of individuals of the most abundant species, $\omega_{i j}$ is the "distinctness weight" given to the path length linking species $i$ to the first common node with species $j$ in the hierarchical classification. Double summations are over all pairs of species $i$ and $j$ (note that the distance between 2 individuals of the same species is set to 0 ). Indices based on presence-absence data are marked by ${ }^{1}$ (after Mérigot et al. 2007a) 
Table 2 Spearman rank correlation coefficients calculated between all the species diversity descriptors considered in the a) Gulf of Lions (area 4 on Fig. 1), b) South West Adriatic (area 16), c) Tyrrhenian Sea (areas 5 to 11), d) Adriatic Sea (areas 16 to 20), e) Western basin (areas 1 to 11), f) Eastern basin (areas 12 to 23), and g) whole MEDITS scale. All correlations are significantly different from zero (with $P<0.05$ ), except for underlined values. The Spearman coefficient distribution under null hypothesis was approximated by a normal distribution with mean equal to 0 and standard deviation equal to $1 / \sqrt{ }(n-1)$. Codes of diversity indices are given in Table 1.

a)

\begin{tabular}{llllllllllll}
\hline & $S$ & $D_{\mathrm{mg}}$ & $H^{\prime}$ & $1-D$ & $E_{\text {Heip }}$ & $1 / d$ & $\Delta$ & $\Delta^{*}$ & $\Delta^{+}$ & $\Lambda^{+}$ & Rarity \\
\hline$S$ & 1 & & & & & & & & & & \\
$D_{\mathrm{mg}}$ & 0.81 & 1 & & & & & & & & & \\
$H^{\prime}$ & 0.33 & 0.61 & 1 & & & & & & & & \\
$1-D$ & 0.22 & 0.49 & 0.97 & 1 & & & & & & & \\
$E_{\text {Heip }}$ & -0.15 & 0.22 & 0.85 & 0.88 & 1 & & & & & \\
$1 / d$ & 0.14 & 0.39 & 0.87 & 0.96 & 0.84 & 1 & & & & \\
$\Delta$ & 0.23 & 0.51 & 0.95 & 0.98 & 0.87 & 0.92 & 1 & & & & \\
$\Delta^{*}$ & 0.21 & 0.28 & 0.34 & 0.29 & 0.25 & 0.20 & 0.45 & 1 & & & \\
$\Delta^{+}$ & 0.19 & $\underline{0.03}$ & $\underline{0.00}$ & $\underline{-0.01}$ & $\underline{-0.10}$ & $\underline{0.01}$ & $\underline{0.02}$ & 0.15 & 1 & & \\
$\Lambda^{+}$ & 0.38 & 0.37 & 0.19 & 0.16 & $\underline{0.01}$ & 0.12 & 0.14 & $\underline{0.01}$ & 0.19 & 1 & \\
Rarity & $\underline{0.11}$ & 0.13 & 0.13 & $\underline{0.11}$ & 0.12 & $\underline{0.07}$ & 0.12 & $\underline{0.07}$ & -0.13 & 0.20 & 1 \\
\hline
\end{tabular}

b)

\begin{tabular}{|c|c|c|c|c|c|c|c|c|c|c|c|}
\hline & $S$ & $D_{\mathrm{mg}}$ & $H^{\prime}$ & $1-D$ & $E_{\text {Heip }}$ & $1 / d$ & $\Delta$ & $\Delta^{*}$ & $\Delta^{+}$ & $\Lambda^{+}$ & Rarity \\
\hline$S$ & 1 & & & & & & & & & & \\
\hline$D_{\mathrm{mg}}$ & 0.79 & 1 & & & & & & & & & \\
\hline$H^{\prime}$ & 0.41 & 0.73 & 1 & & & & & & & & \\
\hline
\end{tabular}




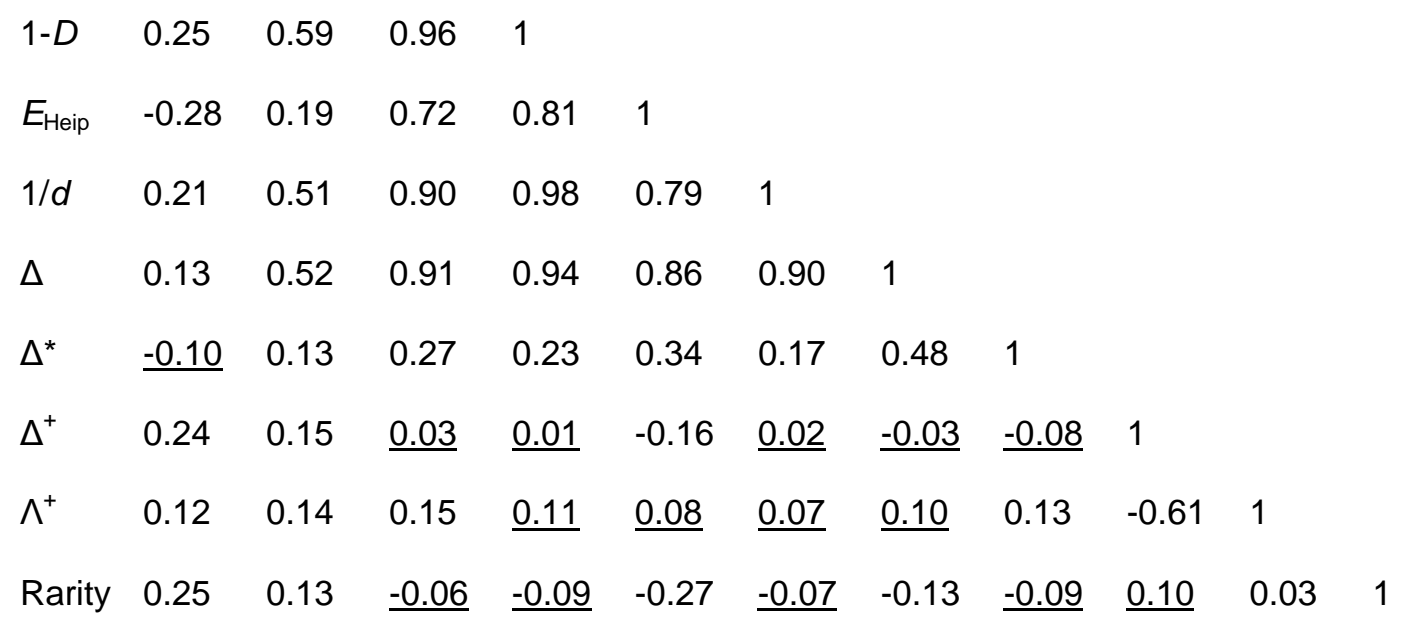

c)

\begin{tabular}{|c|c|c|c|c|c|c|c|c|c|c|c|}
\hline & $S$ & $D_{\mathrm{mg}}$ & $H^{\prime}$ & $1-D$ & $E_{\text {Heip }}$ & $1 / d$ & $\Delta$ & $\Delta^{*}$ & $\Delta^{+}$ & $\wedge^{+}$ & Rarity \\
\hline$S$ & 1 & & & & & & & & & & \\
\hline$D_{\mathrm{mg}}$ & 0.77 & 1 & & & & & & & & & \\
\hline$H^{\prime}$ & 0.38 & 0.67 & 1 & & & & & & & & \\
\hline $1-D$ & 0.28 & 0.56 & 0.98 & 1 & & & & & & & \\
\hline$E_{\text {Heip }}$ & -0.17 & 0.25 & 0.81 & 0.85 & 1 & & & & & & \\
\hline $1 / d$ & 0.25 & 0.50 & 0.92 & 0.98 & 0.82 & 1 & & & & & \\
\hline$\Delta$ & 0.29 & 0.55 & 0.90 & 0.91 & 0.77 & 0.89 & 1 & & & & \\
\hline$\Delta^{*}$ & 0.09 & 0.13 & 0.08 & 0.07 & $\underline{0.02}$ & 0.07 & 0.40 & 1 & & & \\
\hline$\Delta^{+}$ & 0.22 & $\underline{0.02}$ & -0.14 & -0.14 & -0.26 & -0.12 & 0.07 & 0.51 & 1 & & \\
\hline$\Lambda^{+}$ & 0.18 & 0.18 & 0.24 & 0.22 & 0.16 & 0.21 & 0.09 & -0.28 & -0.24 & 1 & \\
\hline Rarity & 0.09 & $\underline{0.05}$ & 0.10 & 0.08 & $\underline{0.04}$ & 0.07 & $\underline{0.05}$ & $\underline{-0.04}$ & $\underline{0.01}$ & 0.23 & 1 \\
\hline
\end{tabular}

d)

\begin{tabular}{|c|c|c|c|c|c|c|c|c|c|c|c|}
\hline & $S$ & $D_{\mathrm{mg}}$ & $H^{\prime}$ & 1-D & $E_{\text {Heip }}$ & $1 / d$ & $\Delta$ & $\Delta^{*}$ & $\Delta^{+}$ & $\Lambda^{+}$ & Rarity \\
\hline $\bar{S}$ & 1 & & & & & & & & & & \\
\hline$D_{\mathrm{mg}}$ & 0.83 & 1 & & & & & & & & & \\
\hline$H^{\prime}$ & 0.47 & 0.7 & 1 & & & & & & & & \\
\hline $1-D$ & 0.32 & 0.55 & 0.97 & 1 & & & & & & & \\
\hline
\end{tabular}




$\begin{array}{lllllllllllll}E_{\text {Heip }} & -0.25 & 0.11 & 0.69 & 0.79 & 1 & & & & & \\ 1 / d & 0.26 & 0.48 & 0.91 & 0.98 & 0.78 & 1 & & & & \\ \Delta & 0.28 & 0.55 & 0.93 & 0.94 & 0.79 & 0.91 & 1 & & & \\ \Delta^{*} & 0.14 & 0.31 & 0.35 & 0.31 & 0.29 & 0.26 & 0.55 & 1 & & \\ \Delta^{+} & 0.42 & 0.36 & 0.18 & 0.11 & -0.13 & 0.09 & 0.16 & 0.26 & 1 & & \\ \Lambda^{+} & 0.38 & 0.25 & 0.12 & \underline{0.05} & -0.18 & \underline{0.01} & \underline{0.03} & \underline{0.03} & \underline{0.04} & 1 & \\ \text { Rarity } & 0.36 & 0.21 & \underline{0.04} & \underline{-0.01} & -0.23 & \underline{-0.02} & \underline{-0.01} & 0.06 & 0.30 & 0.34 & 1\end{array}$

e)

\begin{tabular}{llllllllllll}
\hline & $S$ & $D_{\mathrm{mg}}$ & $H^{\prime}$ & $1-D$ & $E_{\text {Heip }}$ & $1 / d$ & $\Delta$ & $\Delta^{*}$ & $\Delta^{+}$ & $\Lambda^{+}$ & Rarity \\
\hline$S$ & 1 & & & & & & & & & & \\
$D_{\mathrm{mg}}$ & 0.80 & 1 & & & & & & & & & \\
$H^{\prime}$ & 0.38 & 0.67 & 1 & & & & & & & & \\
$1-D$ & 0.27 & 0.54 & 0.97 & 1 & & & & & & & \\
$E_{\text {Heip }}$ & -0.20 & 0.20 & 0.79 & 0.84 & 1 & & & & & \\
$1 / d$ & 0.23 & 0.47 & 0.91 & 0.97 & 0.81 & 1 & & & & \\
$\Delta$ & 0.29 & 0.55 & 0.90 & 0.92 & 0.76 & 0.89 & 1 & & & \\
$\Delta^{*}$ & 0.12 & 0.15 & 0.07 & $\underline{0.04}$ & $\underline{0.00}$ & $\underline{0.02}$ & 0.36 & 1 & & \\
$\Delta^{+}$ & 0.31 & 0.10 & -0.10 & -0.12 & -0.29 & -0.11 & 0.08 & 0.46 & 1 & & \\
$\Lambda^{+}$ & 0.17 & 0.19 & 0.25 & 0.23 & 0.17 & 0.22 & 0.11 & -0.24 & -0.21 & 1 & \\
Rarity & 0.17 & 0.12 & 0.12 & 0.10 & $\underline{0.02}$ & 0.08 & 0.07 & $\underline{-0.02}$ & $\underline{0.01}$ & 0.23 & 1 \\
\hline
\end{tabular}

f)

\begin{tabular}{|c|c|c|c|c|c|c|c|c|c|c|c|}
\hline & $S$ & $D_{\mathrm{mg}}$ & $H^{\prime}$ & $1-D$ & $E_{\text {Heip }}$ & $1 / d$ & $\Delta$ & $\Delta^{*}$ & $\Delta^{+}$ & $\Lambda^{+}$ & Rarity \\
\hline$S$ & 1 & & & & & & & & & & \\
\hline$D_{\mathrm{mg}}$ & 0.83 & 1 & & & & & & & & & \\
\hline$H^{\prime}$ & 0.47 & 0.70 & 1 & & & & & & & & \\
\hline $1-D$ & 0.32 & 0.56 & 0.97 & 1 & & & & & & & \\
\hline
\end{tabular}




$\begin{array}{lllllllllllll}E_{\text {Heip }} & -0.24 & 0.14 & 0.70 & 0.80 & 1 & & & & & \\ 1 / d & 0.26 & 0.48 & 0.91 & 0.98 & 0.79 & 1 & & & & & \\ \Delta & 0.28 & 0.54 & 0.91 & 0.93 & 0.78 & 0.90 & 1 & & & \\ \Delta^{*} & 0.14 & 0.19 & 0.17 & 0.13 & 0.11 & 0.11 & 0.42 & 1 & & & \\ \Delta^{+} & 0.29 & 0.20 & 0.06 & \underline{0.02} & -0.15 & \underline{0.02} & 0.16 & 0.45 & 1 & & \\ \Lambda^{+} & 0.39 & 0.24 & 0.15 & 0.10 & -0.13 & 0.07 & 0.06 & \underline{0.00} & 0.07 & 1 & \\ \text { Rarity } & 0.29 & 0.18 & \underline{0.03} & \underline{-0.01} & -0.19 & \underline{-0.03} & \underline{-0.01} & 0.05 & 0.19 & 0.24 & 1\end{array}$

g)

\begin{tabular}{llllllllllll}
\hline & $S$ & $D_{\mathrm{mg}}$ & $H^{\prime}$ & $1-D$ & $E_{\text {Heip }}$ & $1 / d$ & $\Delta$ & $\Delta^{*}$ & $\Delta^{+}$ & $\Lambda^{+}$ & Rarity \\
\hline$S$ & 1 & & & & & & & & & & \\
$D_{\mathrm{mg}}$ & 0.82 & 1 & & & & & & & & & \\
$H^{\prime}$ & 0.42 & 0.68 & 1 & & & & & & & & \\
$1-D$ & 0.29 & 0.55 & 0.97 & 1 & & & & & & & \\
$E_{\text {Heip }}$ & -0.24 & 0.15 & 0.74 & 0.81 & 1 & & & & & \\
$1 / d$ & 0.24 & 0.47 & 0.91 & 0.98 & 0.79 & 1 & & & & \\
$\Delta$ & 0.28 & 0.54 & 0.91 & 0.92 & 0.76 & 0.89 & 1 & & & & \\
$\Delta^{*}$ & 0.13 & 0.17 & 0.11 & 0.08 & 0.05 & 0.06 & 0.38 & 1 & & & \\
$\Delta^{+}$ & 0.26 & 0.13 & -0.03 & -0.06 & -0.21 & -0.05 & 0.11 & 0.46 & 1 & & \\
$\Lambda^{+}$ & 0.30 & 0.23 & 0.20 & 0.16 & $\underline{0.00}$ & 0.14 & 0.08 & -0.11 & -0.07 & 1 & \\
Rarity & 0.23 & 0.16 & 0.08 & 0.05 & -0.08 & 0.03 & 0.03 & $\underline{0.02}$ & 0.10 & 0.23 & 1 \\
\hline
\end{tabular}


Table 3 PCA based on the Spearman's rank correlation matrix: percentage of inertia accounted for the first four axes.

$\begin{array}{lllll}\text { Axis } 1 & \text { Axis } 2 & \text { Axis } 3 & \text { Axis } 4 & \text { Cumulated inertia }\end{array}$

(first four axes)

\begin{tabular}{|c|c|c|c|c|c|}
\hline \multicolumn{6}{|l|}{ Region } \\
\hline Gulf of Lions (199) & 47.10 & 17.84 & 10.50 & 8.43 & 83.86 \\
\hline $\begin{array}{l}\text { South West Adriatic } \\
(203)\end{array}$ & 46.13 & 18.76 & 14.05 & 8.26 & 87.20 \\
\hline \multicolumn{6}{|l|}{ Biogeographical zone } \\
\hline Tyrrhenian (744) & 46.25 & 17.30 & 14.09 & 9.30 & 86.94 \\
\hline Adriatic (731) & 47.04 & 21.85 & 9.62 & 7.86 & 86.37 \\
\hline \multicolumn{6}{|l|}{ Basin } \\
\hline Western basin (1166) & 45.82 & 18.21 & 13.80 & 8.62 & 86.45 \\
\hline Eastern basin (1238) & 45.73 & 20.32 & 12.23 & 7.70 & 85.98 \\
\hline northern & 45.42 & 18.59 & 13.58 & 8.42 & 86.01 \\
\hline $\begin{array}{l}\text { Mediterranean } \\
(2404)\end{array}$ & & & & & \\
\hline
\end{tabular}

Note: The number of stations analyzed for each area is given into brackets. 
Appendix A List of the species considered.

Aphia minuta (Risso 1810)

Argentina sp

Arnoglossus imperialis* (Rafinesque 1810)

Arnoglossus laterna (Walbaum 1792)

Arnoglossus rueppelii (Cocco 1844)

Arnoglossus thori (Kyle 1913)

Aspitrigla cuculus (Linnaeus 1758)

Blennius ocellaris (Linnaeus 1758)

Boops boops (Linnaeus 1758)

Bothus podas* (Delaroche 1809)

Buglossidium luteum* (Risso 1810)

Callionymus sp

Capros aper (Linnaeus 1758)

Carapus acus (Brünnich 1768)

Centracanthus cirrus (Rafinesque 1810)

Cepola macrophthalma (Linnaeus 1758)

Chelidonichthys lastoviza (Bonnaterre 1788)

Chelidonichthys lucernus (Linnaeus 1758)

Chelidonichthys obscurus (Bloch and Schneider 1801)

Citharus linguatula (Linnaeus 1758)

Conger conger (Linnaeus 1758)

Dasyatis pastinaca (Linnaeus 1758)

Deltentosteus quadrimaculatus (Valenciennes 1837)

Dicentrarchus labrax* (Linnaeus 1758)

Diplodus annularis (Linnaeus 1758)

Diplodus vulgaris (Geoffroy Saint-Hilaire 1817)

Echelus myrus (Linnaeus 1758)

Eutrigla gurnardus (Linnaeus 1758)

Gadiculus argenteus argenteus (Guichenot 1850)

Gaidropsarus sp* 
Galeus melastomus* (Rafinesque 1810)

Gobius sp

Helicolenus dactylopterus dactylopterus (Delaroche 1809)

Lepidorhombus boscii (Risso 1810)

Lepidorhombus whiffiagonis* (Walbaum 1792)

Lepidopus caudatus (Euphrasen 1788)

Lepidotrigla cavillone (Lacepède 1801)

Lepidotrigla dieuzeidei (Blanc and Hureau 1973)

Lesueurigobius sp

Lithognathus mormyrus* (Linnaeus 1758)

Lophius budegassa (Spinola 1807)

Lophius piscatorius (Linnaeus 1758)

Macroramphosus scolopax (Linnaeus 1758)

Merluccius merluccius (Linnaeus 1758)

Merlangius merlangus (Linnaeus 1758)

Micromesistius poutassou (Risso 1827)

Microchirus variegatus (Donovan 1808)

Monochirus hispidus (Rafinesque 1814)

Mullus barbatus (Linnaeus 1758)

Mullus surmuletus (Linnaeus 1758)

Mustelus mustelus (Linnaeus 1758)

Ophidion barbatum (Linnaeus 1758)

Ophichthus rufus (Rafinesque 1810)

Pagellus acarne (Risso 1827)

Pagellus bogaraveo (Brünnich 1768)

Pagellus erythrinus (Linnaeus 1758)

Pagrus pagrus* (Linnaeus 1758)

Phycis blennoides (Brünnich 1768)

Peristedion cataphractum (Linnaeus 1758)

Psetta maxima* (Linnaeus 1758) 
Raja asterias (Delaroche 1809)

Raja clavata (Linnaeus 1758)

Scophthalmus rhombus* (Linnaeus 1758)

Scorpaena elongata* (Cadenat 1943)

Scorpaena loppei^ (Cadenat 1943)

Scorpaena notata (Rafinesque 1810)

Scorpaena porcus (Linnaeus 1758)

Scorpaena scrofa (Linnaeus 1758)

Scyliorhinus canicula (Linnaeus 1758)

Serranus cabrilla (Linnaeus 1758)

Serranus hepatus (Linnaeus 1758)

Solea solea (Linnaeus 1758)

Sparus auratus* (Linnaeus 1758)

Sphyraena sphyraena (Linnaeus 1758)

Spicara maena (Linnaeus 1758)

Spicara smaris (Linnaeus 1758)

Spondyliosoma cantharus (Linnaeus 1758)

Squalus acanthias* (Linnaeus 1758)

Symphurus sp

Syngnathus acus (Linnaeus 1758)

Torpedo marmorata (Risso 1810)

Torpedo nobiliana* (Bonaparte 1835)

Trachinus draco (Linnaeus 1758)

Trachinus radiatus* (Cuvier 1829)

Trigla lyra (Linnaeus 1758)

Trisopterus minutus (Linnaeus 1758)

Uranoscopus scaber (Linnaeus 1758)

Zeus faber (Linnaeus 1758)

Notes: Rare species (occurrence $<5 \%$ of the tows for the whole studied zone) are marked by *. Species potentially confused in one area have been clustered at the genus level (e.g. Callionymus $s p$ ). 
